\title{
Attribution of climate extreme events
}

\author{
Article
}

Accepted Version

Trenberth, K. E., Fasullo, J. T. and Shepherd, T. G. (2015) Attribution of climate extreme events. Nature Climate Change, 5 (8). pp. 725-730. ISSN 1758-678X doi: https://doi.org/10.1038/nclimate2657 Available at https://centaur.reading.ac.uk/40583/

It is advisable to refer to the publisher's version if you intend to cite from the work. See Guidance on citing.

Published version at: http://dx.doi.org/10.1038/nclimate2657

To link to this article DOI: http://dx.doi.org/10.1038/nclimate2657

Publisher: Nature Publishing Group

All outputs in CentAUR are protected by Intellectual Property Rights law, including copyright law. Copyright and IPR is retained by the creators or other copyright holders. Terms and conditions for use of this material are defined in the End User Agreement.

\section{www.reading.ac.uk/centaur}

\section{CentAUR}

Central Archive at the University of Reading

Reading's research outputs online 


\section{Attribution of climate extreme events}

Kevin E Trenberth ${ }^{1}$, John T. Fasullo ${ }^{1}$

and Theodore G. Shepherd ${ }^{2}$

1. National Center for Atmospheric Research (NCAR)

P.O. Box 3000

Boulder CO 80307

2. Department of Meteorology, University of Reading, Reading RG6 6BB, UK

Phone: (303) 4971318

Fax: (303) 4971333

email: trenbert@ucar.edu

Nature Climate Change

Perspective

8 October 2014

12 November 2014 (revised)

7 January 2015 (revised)

17 March 2015 (revised)

8 April 2015 (final)

Abstract 171 words

Text 4104 words

References: 38

Figures 5 
There is a tremendous desire to attribute causes to weather and climate events that is often challenging from a physical standpoint. Headlines attributing an event solely to either human-induced climate change or natural variability can be misleading when both are invariably in play. The conventional attribution framework struggles with dynamically-driven extremes because of the small signal-to-noise and often uncertain nature of the forced changes. Here, we suggest that a different framing is desirable, which asks why such extremes unfold the way they do. Specifically, that it is more useful to regard the extreme circulation regime or weather event as being largely unaffected by climate change, and question whether known changes in the climate system's thermodynamic state affected the impact of the particular event. Some examples briefly illustrated include "snowmaggedon" in February 2010, super storm Sandy in October 2012, and super typhoon Haiyan in November 2013 and, in more detail, the Boulder floods of September 2013, all of which were influenced by high sea surface temperatures that had a discernible human component.

Weather and climate extremes happen all of the time, even in an unchanging climate. Yet there is a justifiably strong sense that some of these extremes are changing to be more frequent, and that the main reason is because of human-induced climate change. Indeed, the main way climate change is likely to be manifested on societies around the world is through changes in extremes. As a result, the scientific community faces an increasing demand for regularly updated appraisals of evolving climate conditions and extreme weather. Such information would be immensely beneficial for adaptation planning.

The large-scale atmospheric circulation determines where it is dry, where it is wet, where it is hot, and so on. A recent example is documented for the Pacific Northwest ${ }^{1}$. Yet as discussed below, in contrast to thermodynamic aspects of climate, forced circulation changes in climate models can be very non-robust, and physical understanding of the causes of these changes is generally lacking2. Therefore, we suggest that separating out the thermodynamic from dynamic effects may be a very fruitful way forward and result in a different set of questions to be addressed. In turn, these provide a better basis for communication of climate change to the public.

\section{Complexities associated with extreme event attribution}

The climate community has responded to the demand for timely information by attempting to perform attribution of climate extremes, both through the Intergovernmental Panel on Climate Change (IPCC) ${ }^{3}$ reports but most evident in closer to real time through an annual report, the most recent of which - "Explaining extreme events of 2013 from a climate perspective" - was published by the American Meteorological Society in September 2014 and reported on several events from 2013. The question posed in each case was whether the likelihood or strength of the event was affected by anthropogenic climate change.

More generally, there are perhaps two main kinds of attribution performed. The first relates the particular extreme event to the associated weather and weather patterns, and this has been a useful and long-standing activity in climate science. We hear statements 
like "the drought was caused by a blocking anticyclone"; or the "outbreak of tornadoes was caused by a displaced and active storm track and jet stream"; "the flooding was caused by El Niño", and so on. However, because these studies relate the event and phenomenon to the weather situation or weather pattern, they are really a description of the event, not a cause. As an explanation, the question should be, "why did that weather phenomenon behave the way it did?" In particular, "what influences external to the atmosphere were playing a role and what climate factors were in play?"

The second kind of attribution relates especially to the objective of assessing the role of human activities, and especially human-induced climate change in the event. Or perhaps this might be generalized to a goal of assessing the role of external influences in the climate system on the event in question. So as well as human influences there may be influences from volcanic eruptions or the sun. However, results depend upon how questions are framed ${ }^{5-7}$.

The conventional approach to attribution of climate events is described by Stott et al. ${ }^{8}$. Clearly, it is not possible to attribute a single climate extreme event, which by definition is unique and which has a large element of chance in its occurrence, to a specific cause. Thus, the approach is to characterize the event and ask (i) whether the likelihood or strength of such events has changed in the observational record, and (ii) whether this change is consistent with the anthropogenic influence as found in one or more climate models, and thereby assess the "Fraction of Attributable Risk". The conventional approach has had considerable success with extremes that are strongly governed by thermodynamic aspects of climate change, especially those related to temperature. Since the attribution is unconditional - the null hypothesis is that there is no effect of climate change - each finding provides another independent line of evidence that anthropogenic climate change is affecting climate extremes.

However, the conventional approach is severely challenged when it comes to climate extremes that are strongly governed by atmospheric circulation, including local aspects of precipitation. The main reason is because changes in the atmospheric circulation related to climate change are fairly small compared to natural variability, as has been shown especially by several studies at NCAR using "large ensembles" 10 for 60 years into the future. While large changes in atmospheric circulation can be readily apparent in a single climate model run, they are not robust and change a lot in the next run or model. Indeed what have often been interpreted as differences between models used in IPCC reports may have arisen at least in part from natural variability. Hence forced circulation changes are not well established and it is difficult to detect changes in circulation-related extremes in observations because of small signal-to-noise. Thus, the anomalous weather pattern is always the dominant influence for all short-lived events of a week or two, and this is generally true even for years or decades. Accordingly, the conventional approach to extreme event attribution is rather ineffectual in cases that rely on the changed circulation, with generally an inconclusive outcome. Even when a detectable anthropogenic influence is found in a model, the reliability of that finding cannot carry much weight. 
Yet from a risk perspective, it is still important to assess the likely anthropogenic impact on such events. By starting from the null hypothesis of no climate change, the conventional approach to extreme-event attribution has to re-establish an anthropogenic influence for each kind of event $a b$ initio, which makes it inherently conservative and prone to "Type II errors" which underestimate the true likelihood of the human influence ${ }^{5,6}$. Given that we have a large amount of confidence in many aspects of climate change ${ }^{3}$, it seems rather peculiar to ignore that prior knowledge in our assessment of climate events 5 .

As noted above the predictability of the dynamics is problematical ${ }^{2}$ and it is mainly through the thermodynamics that reliable statements can be made with confidence about the role of climate change. In other words, changes in temperatures and temperature extremes have a much more robust basis. That carries over to the atmospheric moisture amounts through the Clausius-Clapeyron equation in which the water-holding capacity of the atmosphere goes up exponentially at a rate of about $7 \%$ per degree Celsius. Indeed this is what is observed in actual changes in moisture in the atmosphere over the oceans and where surface moisture is not limited. But over land, especially in summer, water availability is also a vital factor ${ }^{11}$. Because the main rainfall almost always comes from moisture convergence in the atmosphere, increased water vapor in the environment leads to more intense rains and a risk of flooding 12,13 , even if the total amount does not change much. Moreover, it is in droughts that the extra heat from increased greenhouse gases accumulates whereas more generally the presence of surface moisture adds an evaporative cooling effect.

\section{More fruitful scientific questions}

One can ask questions such as: What was the role of internal natural variability in setting up the pattern? Studies to explore this question include those documenting the role of anomalous SSTs and especially El Niño-Southern Oscillation (ENSO), the Pacific Decadal Oscillation (PDO) ${ }^{14}$, the North Atlantic Oscillation (NAO), and other so-called modes of variability. In general, it may not be possible to say much concrete about regional climate change unless one can understand and predict such modes of variability and their statistics. ENSO may be predictable for up to 18 months or so, some decadal predictability may exist for decadal modes for several years ${ }^{15}$, but in general chaotic elements in the weather and climate system preclude longer-term statements because these regional patterns are not externally forced.

In most of these cases, the result of these studies will be a description of the large-scale patterns, the anomalous SSTs, and the relationships between the atmospheric circulation, storm tracks, blocking, temperatures and precipitation, and perhaps extremes. If considered, this part will undoubtedly conclude that greenhouse gas forcing or aerosols played little or no role in the circulation changes, although sometimes claims otherwise are made.

Instead, with regard to climate change, the questions to be answered could be:

- Given the weather pattern, how were the temperatures, precipitation, and associated impacts influenced by climate change? 
- Given a drought, how was the drying (evapotranspiration) enhanced by climate change and how did that influence the moisture deficits and dryness of soils, and wild fire risk? Did it lead to a more intense and perhaps longer lasting drought, as is likely ${ }^{16,17}$ ?

- Given a flood, where did the moisture come from? Was it enhanced by high ocean temperatures that may have had a climate change component?

- Given a heat wave, how was that influenced by drought, changes in precipitation (absence of evaporative cooling from dry land), and extra heat from global warming?

- Given extreme snow, where did the moisture come from? Was it related to higher than normal SSTs off the coast or farther afield?

- Given an extreme storm, how was it influenced by anomalous SSTs and ocean heat content, anomalous moisture transports into the storm, and associated rainfall and latent heating? Was the storm surge worse because of high sea levels?

In other words, given the change in atmospheric circulation that brought about the event, how did climate change alter its impacts?

To summarize therefore, at least in the present state of knowledge, in our view a more fruitful and robust approach to climate extreme-event attribution is to regard the circulation regime or weather event as a conditional state (whose change in likelihood is not assessed), and ask whether the impact of the particular event was affected by known changes in the climate system's thermodynamic state (e.g., sea level, sea surface temperature, or atmospheric moisture content), concerning which there is a reasonably high level of confidence. Such questions immediately lead to a physically-based approach that is strongly linked to the event in question. Although such questions differ from the conventional "frequentist" approach, they are perfectly reasonable from a Bayesian perspective, which can accommodate questions about single events ${ }^{18}$. Because the questions are posed differently, their answers have a different meaning and focus more on impacts. That is still useful information.

Frequently, the main influences identified external to the atmosphere are the changes in SSTs. Of course the SSTs at any time have a large natural variability component but the values are very often inflated over what they would have been without climate change. The latter accounts for order $0.6^{\circ} \mathrm{C}$ increase since the 1950 s globally $^{3}$ and because this inherently occurs on multi-decadal timescales with a memory through the ocean heat content, it is always present. Small increases in atmospheric moisture associated with such an increase in SSTs are of order 5\% (ref. 19). We also assume that the global sea level rise for the past century of $19 \mathrm{~cm}$ (1901-2010) ${ }^{3}$ reflects the underlying human influence while regional values vary owing to atmospheric circulation variations.

\section{Some examples}

The following examples briefly discuss a few events whose attribution has not been addressed but which received an enormous amount of media attention. 
219 Consider the widely publicized event called "snowmaggedon" in Washington, DC 20 in

220 February 5-6, 2010. Key features included (1) it was winter and there was plenty of cold

221 continental air; (2) there was a storm in the right place; and (3) the unusually high SSTs in

222 the tropical Atlantic Ocean $\left(1.5^{\circ} \mathrm{C}\right.$ above normal) led to an exceptional amount of moisture

223 flowing into the storm, which resulted in very large snow amounts. It is this last part that

224 then relates in part to anomalous external influences on the atmosphere through the effects

225 of climate change on SSTs. So while internal variability is also playing a role, the extremes

226 are magnified by climate change.

227

228

229

230

231

232

233

234

235

236

237

238

239

240

241

242

243

244

245

246

247

248

249

250

251

252

253

254

255

256

257

258

259

260

261

262

263

264

Super-storm Sandy caused tremendous damage when it made landfall on the New Jersey coast and New York area on 30 October 2012. It began as a hurricane, with peak strengths making it a category 3 storm, and it caused substantial impacts in the Caribbean ${ }^{21}$.

However, as it moved north it became a hybrid storm before making landfall, which greatly increased its overall size. The worst problems on the Jersey Shore were caused by the strong winds and the associated storm surge, leading to extensive flooding. Farther inland, heavy precipitation was also a major problem. Widespread damage from flooding streets, tunnels and subway lines and cutting power in and around New York City led to damages exceeding $\$ 65$ billion (2013 USD) ${ }^{22}$. Fortunately, the storm was well forecast a week in advance in particular by European Centre for Medium-Range Weather Forecasts (ECMWF), including the very unusual left hook turn in the track toward the coast. ECMWF has performed a number of experiments on the performance and behavior of the storm using an ensemble of forecasts five days in advance of landfall ${ }^{23}$. Of note is that they swapped the observed SSTs for climatological values that average 1 to $1.5^{\circ} \mathrm{C}$ cooler in a broad strip along the coast. Only small changes occurred to the track of the storm but the observed SSTs led to a bigger more intense storm, stronger winds and greater precipitation. The average depth of the storm was increased by $7.6 \mathrm{hPa}$, the wind speeds were increased by $3.6 \mathrm{~m} \mathrm{~s}^{-1}$ and the precipitation increased by $35 \%$. Moreover the storm was riding on sea levels that were higher by about $19 \mathrm{~cm}$ due to global warming. Although perhaps only one-half to one-third of the SST increase can be blamed on global warming from human activities, it is readily apparent that the storm surge and associated damage was considerably influenced by climate change. It is quite possible that the subways and tunnels may not have flooded without the warming-induced increase in sea level and storm intensity and size, putting a potential price tag of human climate change in this storm in the tens of billions of dollars.

Another example is super typhoon Haiyan ${ }^{24}$ that devastated the Philippines in early November 2013. It is among the largest and most intense typhoons on record with estimated surface pressure in the eye down to $895 \mathrm{hPa}$ and 1-minute sustained winds of $315 \mathrm{~km} / \mathrm{h}$ (gusts to $378 \mathrm{~km} / \mathrm{h}$ ) on November 7, 2013 which makes it the strongest recorded storm to ever strike land (Fig. 1). It has been called a "category 6" storm ${ }^{25}$. The ocean heat content (OHC) and sea level in the region had increased a great deal since 1993 and especially since 1998 in association with the PDO negative phase ${ }^{26,14}$ so that since 1993 the linear trend in sea level was over $16 \mathrm{~mm} / \mathrm{yr}$ as compared to the global trend of $3.3 \mathrm{~mm} / \mathrm{yr}$ (Fig. 1; using data from AVISO ${ }^{27}$ ). Consequently, as the typhoon approached the Philippines, it was riding on very high SSTs with very deep support through the high OHC, and the strong winds and ocean mixing did not cause as much cooling as would normally be experienced, very likely helping the storm to maintain its tremendous strength ${ }^{25}$. 
Moreover, the storm surge was undoubtedly exacerbated considerably by the sea levels that were some $30 \mathrm{~cm}$ above 1993 values. Although natural variability through the PDO played a major role, there is also a global component through increased $\mathrm{OHC}$ from the Earth's energy imbalance ${ }^{28}$.

A conclusion then, is that while climate change is no doubt altering the atmospheric circulation, the change is relatively small and can only be discerned from a very large ensemble of model runs. That sets the change in odds. But for any event, the particular character of that storm or synoptic situation and natural variability rule, while thermodynamic effects increase the impacts.

\section{A case in point: the Boulder floods of September 2013}

One of the recent BAMS studies is of the major floods centered in Boulder in September $2013^{29}$. The unfortunate headline of the news release which carried over in large letters to the front page of the local newspaper in Boulder (Daily Camera 30 Sept 2014) ${ }^{30}$ was: "Climate change not to blame for 2013 Colorado floods". The paper summary was: "The probability for an extreme five-day September rainfall event over northeast Colorado, as was observed in early September 2013, has likely decreased due to climate change."

As noted above, in any weather event like this, the weather situation is always the main player in the developments but that in and of itself says nothing about the role of climate change. The study did note the importance of having abundant moisture in the region in order to produce high rainfall amounts. But it did not include an assessment as to where the moisture came from. In Denver the three highest total column water vapor amounts ever recorded for September (since 1956) occurred on 12-13 September 2013 (as high as $34 \mathrm{~mm}$ ). [This may not seem huge but recall Denver is a mile (>1600 m) above sea level].

It so happens that the SSTs off the West Coast of Mexico, south of Baja, west of Guadalajara, were over $30^{\circ} \mathrm{C}$ and more than $1^{\circ} \mathrm{C}$ above normal in August 2013 (see Fig. 2), which made it the hottest spot for the ocean in the western hemisphere. An incredible $75 \mathrm{~mm}$ of total column water vapor was recorded in the atmosphere in that region by NASA satellites. The high SSTs led to the large-scale convergence of moisture flowing into the region that was siphoned north by a very unusual synoptic situation leading to a river of atmospheric moisture flowing into Colorado (Figs. 3 and 4). The heaviest moisture convergence into eastern Colorado coincided with the times of the plots in Fig. 4, while breaks in the rain occurred in between times in some locations (Fig. 3). After that river shut off, twin tropical storms formed both sides of Mexico: Manuel (to the west) ${ }^{31}$ and Ingrid (to the east) ${ }^{32}$ (Fig. 5) that formed a double whammy for Mexico and led to hundreds of deaths, tens of thousands evacuated, tens of thousands of homes damaged and billions of dollars of damage ${ }^{31,32}$.

Experience with simulations of atmospheric rivers at NCAR has shown that quite high resolution of order one quarter the size of that used by Hoerling et al. ${ }^{29}$ is required to perform realistic simulations, and coarse resolution can lead to discrepancies in the atmospheric moisture amounts simulated. Hoerling et al. ${ }^{29}$ is likely correct in concluding 
311 that the set up of weather systems was rare, and climate change is not a discernible factor

312 in that respect. However, one cannot realistically do attribution using a model that does

313 not have the requisite spatial resolution to represent the relevant dynamics and is unable

314 to replicate the event in question, and it is desirable to use more than one model. Moreover,

315 the extremely high SSTs and record water vapor amounts that accompanied the event and

316 were instrumental in its evolution likely would not have occurred without climate change.

317 Even a 10\% increase in moisture in the atmosphere becomes concentrated when focused

318 by topography, and further amplified when on the ground as water drains into channels

319 and rivers.

320

321

322

323

324

325

326

327

328

329

330

331

332

333

334

335

336

337

338

339

340

341

342

343

344

345

346

347

348

349

350

351

352

353

354

355

356

SSTs have been as high in the past in this region west of Mexico (Fig. 2), but in previous cases they were part of a much larger-scale pattern associated with El Niño events such as in 1997-98, 2004-5, 2009-10. What seems to be unique in 2013 is that this was the warmest spot in the western hemisphere and hence this was the preferred location for low pressure to form and low-level wind convergence, which brought large amounts of moisture into the region. Hence there was clearly an internal variability component to the patterns of SST, but at the same time, the overall increase of global SST associated with global warming that occurs on multi-decadal time scales was also a factor. In Fig. 2 this warming is especially evident after 1997 when SSTs average $>0.4^{\circ} \mathrm{C}$ above the mean.

\section{Concluding remarks}

We have suggested four climate events in which anomalously high SSTs played a key role in feeding moisture into storms, helping to intensify the storm and causing heavy rains. Of course the SSTs at any time have a large natural variability component on top of the human-induced warming. Associated increases in atmospheric moisture are of order 5\% (ref. 19), which is magnified as moisture converges into a storm, further magnified as the storm intensifies, and concentrated when it runs up against orography, and in streamflows. Hence even though natural variability always dominates in such storms, the research task is to refine the above estimates and properly account for the human component as at least a partial explanation for why extremes are being magnified.

There are many other possible examples. For instance, conflicting results occurred for the Russian heat wave in $2010^{33,34}$ that were to some extent reconciled ${ }^{35}$ by recognizing that each study was about different aspects. One study ${ }^{33}$ focused on dynamical aspects while the other ${ }^{34}$ was much more about the record high temperatures and thermodynamic aspects. Indeed, the record high SSTs and associated nearby rains in several areas (including the Pakistan floods) were factors external to the atmosphere ${ }^{36}$ that altered teleconnections into the Russian region.

Another very recent example is the California drought beginning in 2012. While one study ${ }^{37}$ found no significant trends in winter precipitation in recent decades, another ${ }^{38}$ pointed out the critical role of the record high annual mean temperatures in combination with record low annual mean precipitation for 2013 which led to increased evapotranspiration and more intense drought that had impacts on water shortages, vegetation and agriculture, and increased wildfire risk. The odds of this combination have 
357 increased with human-induced climate change and that anthropogenic warming has 358 increased drought risk ${ }^{39}$. Again these two studies are consistent with the view that the atmospheric circulation changes are not the dominant factor as far as the climate change aspects are concerned.

In addition there were 22 articles in the special BAMS issue 4 . Over two-thirds focused on aspects of atmospheric circulation and generally concluded there was little or no influence of anthropogenic climate change. None of the eight studies that dealt with heavy rains or snows performed an analysis of the moisture budget and where the abundant water came from. Of the three studies that analyzed the California drought, none dealt with land surface effects or changes in evapotranspiration associated with climate change. In contrast, for the Australian heat wave, the role of decreased soil moisture and drought were noted for their effects on temperatures. The summary Table focused on columns about anthropogenic influences vs no such influence detected.

There are many other examples of studies that might ask more targeted questions that better serve societal needs. Reframing the null hypothesis and asking different questions would help advance the understanding. Because global warming is real and present, it is not a question as to whether it is playing a role but what that role is. A Bayesian approach takes these "priors" appropriately into account. We can talk about these effects in terms of changing odds, as many have done. But we can also talk about them in physical terms.

To implement the approach suggested here, one needs to be able to simulate the event in question (perhaps with short-term forecasts, as in the Sandy example, or with simulations whose circulation is constrained in some manner), and then assess the impact of known anthropogenic changes in the climate system's thermodynamic state, including changed amounts of water vapor. Only in this way can the necessarily conditional nature of the event attribution be implemented. Necessarily this addresses only a subset of the possible influences and conditions. However, with the underlying assumption that the phenomena are largely unchanged, this is perhaps as much as can be expected for event attribution. After all a single extreme event is not a repeatable thing.

The climate is changing: we have a new normal! The environment in which all weather events occur is different than it used to be. All storms, without exception, are different. Even if most of them look just like the ones we used to have, they are not the same. However, we cannot sort out these questions of degree without a large ensemble of model simulations, particularly for events as rare as the Boulder floods, and the kinds of models that can be run in such a way are often incapable of simulating the event in question and thus lack physical credibility. We argue that under such conditions it is better for event attribution to focus not on the synoptic event, but rather on the influences of the changed large-scale thermodynamic environment on the extremes and temperatures and moisture associated with the event. 
1. Johnstone, J. A., \& Mantua, N. J. Atmospheric controls on northeast Pacific temperature variability and change, 1900-2012. PNAS, doi:10.1073/pnas.1318371111 (2014).

2. Shepherd, T. G. Atmospheric circulation as a source of uncertainty in climate change projections. Nature Geo., 7, 703-708, doi: 10.1038/NGEO2253 (2014).

3. IPCC (Intergovernmental Panel on Climate Change): Climate change 2013: The Physical science basis. Fifth Assessment report of the IPCC [Stocker, T. F. et al. eds)]. Cambridge Univ. Press. 1535 pp. (2013).

4. Herring, S. C., Hoerling, M. P., Peterson T. C. \& Stott, P. A., Eds. Explaining extreme events of 2013 from a climate perspective. Bull. Amer. Meteor. Soc., 95, (9) S1-S96 (2014).

5. Trenberth, K. E. Attribution of climate variations and trends to human influences and natural variability. Wiley Interdisciplinary Reviews (WIREs) Climate Change 2, 925-930, doi: 10.1002/wcc.142 (2011a).

6. Trenberth, K. E. Framing the way to relate climate extremes to climate change. Climatic Change, 115, 283-290, doi: 10.1007/s10584-012-0441-5 (2012).

7. Wallace, J. M. Weather- and climate-related extreme events: Teachable moments. Eos, 93, 11, 13 March, 120-121 (2012).

8. Stott P., et al. Attribution of weather and climate-related extreme events, Chapter 12 in "Climate Science Serving Society", Asrar, G. R. \& Hurrell, J. W., Eds. Springer, 307-337 (2013).

9. Deser, C., Phillips, A., Bourdette, V. \& Teng, H. Y. Uncertainty in climate change projections: the role of internal variability. Clim. Dyn. 38, 527-546 (2012).

10. Deser, C., Phillips, A. S., Alexander, M. A. \& Smoliak, B. V. Projecting North American climate over the next 50 years: uncertainty due to internal variability. J. Clim., 27, 2271-2296 (2014).

11. Trenberth, K. E. Changes in precipitation with climate change. Climate Research, 47, 123-138, doi:10.3354/cr00953 (2011).

12. Trenberth, K. E. Atmospheric moisture residence times and cycling: Implications for rainfall rates with climate change. Climatic Change, 39, 667-694 (1998).

13. Trenberth, K. E., Dai, A., Rasmussen, R. M. \& Parsons, D. B. The changing character of precipitation. Bull. Amer. Meteor. Soc., 84, 1205-1217 (2003).

14. Trenberth, K. E., Fasullo, J. T., Branstator, G. \& Phillips, A. S. Seasonal aspects of the recent pause in surface warming. Nature Climate Change, 4, 911-916, doi:10.1038/NCLIMATE2341 (2014c).

15. Branstator, G. \& Teng, H. Is AMOC more predictable than North Atlantic heat content? J. Clim., 27, 3537-3550 (2014).

16. Seneviratne, S. I., et al. Investigating soil moisture-climate interactions in a changing climate: A review, Earth Sci. Rev., 99, 125-161 (2010).

17. Trenberth, K. E., Dai, A., van der Schrier, G., Jones, P. D., Barichivich, J., Briffa, K. R. \& Sheffield, J. Global warming and changes in drought. Nature Climate Change, 4, 17-22, doi:10.1038/NCLIMATE2067 (2014a).

18. Lyons, L., Discovery or fluke: Statistics in particle physics. Physics Today, 65, (7), 45-51 (2012).

19. Trenberth, K. E., Fasullo, J. \& Smith, L. Trends and variability in column-integrated atmospheric water vapor. Clim. Dynam., 24, 741-758 (2005).

20. http://en.wikipedia.org/wiki/February_5\%E2\%80\%936,_2010_North_American_blizzard

21. Blake, E. S., Kimberlain, T. B., Berg, R. J., Cangialosi, J. P. \& Beven II, J. L. Tropical cyclone report hurricane Sandy. Rep. AL182012, National Hurricane Center, 157 pp (2013).

22. http://en.wikipedia.org/wiki/Hurricane_Sandy

23. Magnusson, L. Bidlot, J-R., Lang, S. T. K., Thorpe, A., Wedi, N. \& Yamaguchi, M. Evaluation of medium-range forecasts for hurricane Sandy. Mon. Wea Rev. 142, 1962-1981 (2014).

24. http://en.wikipedia.org/wiki/Typhoon_Haiyan

25. Lin, I-I., Pun, I-F., \& Lien, C-C. 'Category-6' Supertyphoon Haiyan in global warming hiatus: 

doi: 10.1002/2014GL061281.

26. Trenberth, K. E. \& Fasullo, J. T. An apparent hiatus in global warming? Earth's Future. 1, 19-32, doi: 10.002/2013EF000165 (2013).

27. http://www.aviso.altimetry.fr/en/data/products/ocean-indicators-products/mean-sealevel.html

28. Trenberth, K. E., Fasullo, J. T. \& Balmaseda, M. A. Earth's energy imbalance. J. Clim., 27, 31293144, doi: 10.1175/JCLI-D-13-00294 (2014b).

29. Hoerling, M., et al. Northeast Colorado extreme rains interpreted in a climate change context [in "Explaining Extremes of 2013 from a Climate Perspective"]. Bull. Amer. Meteor. Soc., 95 (9), S15S18 (2014).

30. http://www.dailycamera.com/news/boulder-flood/ci_26626817/boulder-researcher-2013sflood-triggering-rains-not-caused

31. http://en.wikipedia.org/wiki/Hurricane_Manuel

32. http://en.wikipedia.org/wiki/Hurricane_Ingrid

33. Dole, R., Hoerling, M., Perlwitz, J., Eischeid, J., Pegion, P., Zhang, T., Quan, X.-W., Xu, T. \& Murray, D. Was there a basis for anticipating the 2010 Russian heat wave?, Geophys. Res. Lett., 38, L06702, doi:10.1029/2010GL046582 (2011).

34. Rahmstorf, S., \& Coumou, D. Increase of extreme events in a warming world, Proc. Natl. Acad. Sci. U. S. A., 108(44), 17905-17909 (2011).

35. Otto, F. E. L., Massey, N., van Oldenborgh, G. J., Jones, R. G. \& Allen, M. R. Reconciling two approaches to attribution of the 2010 Russian heat wave, Geophys. Res. Lett., 39, L04702, doi:10.1029/2011GL050422 (2012).

36. Trenberth, K. E., \& Fasullo, J. T. Climate extremes and climate change: The Russian heat wave and other climate extremes of 2010, J. Geophys. Res., 117, D17103, doi:10.1029/2012JD018020 (2012).

37. Seager, R, et al. Causes and Predictability of the 2011-14 California Drought. Available at cpo.noaa.gov/sites/cpo/MAPP/Task\%20Forces/DTF/californiadrought/california_drought_re port.pdf (2014).

38. Diffenbaugh, N. S., Swain D. L. \& Touma, D. Anthropogenic warming has increased drought risk in California. PNAS, 112, 3931-3936, doi 10.1073/pnas.1422385112 (2015).

Correspondence and requests for materials should be addressed to K.E.T.

\section{Acknowledgements}

The National Center for Atmospheric Research is sponsored by the National Science Foundation. This work is supported by DOE award DE-SC0012711. TGS acknowledges the support provided through the Grantham Chair in Climate Science at the University of Reading.

\section{Author contributions}

K.E.T led the writing of the paper and conceived of the paper and figures. J.T.F analyzed some data and contributed to 2 figures. All authors contributed to writing the manuscript.

\section{Additional information}

Reprints and permissions information is available online at www.nature.com/reprints.

\section{Competing financial interests}

The authors declare no competing financial interests 
498

499

500

501

502

503

504

505

506

507

508

509

510

511

512

513

514

515

516

517

518

519

520

Figure captions

Fig. 1. Haiyan and sea level: Linear sea level trends from August 1993 to July 2013 in mm/y, from AVISO. The global mean is $3.3 \mathrm{~mm} / \mathrm{y}$ and the track of super Typhoon Haiyan from 311 November 2013 is shown, with the most intense phase when it was a category 5 storm highlighted.

Fig. 2. August SSTs for $12-20^{\circ} \mathrm{N} 110-100^{\circ} \mathrm{W}$, just west of Mexico. The mean value is $28.92^{\circ} \mathrm{C}$ for $1982-1999$. The last value is for 2013 .

Fig. 3. Water vapor channel imagery for 18:45 GMT on 12 September 2013 showing the extensive water vapor and associated activity both west of Mexico and in the Caribbean Sea and the river of moisture from south of Baja, Mexico to eastern Colorado. Courtesy weathertap.com, published with permission.

Fig. 4. GOES 13 imagery from the 6.5 micron water vapor channel at 0545 GMT on 11 (top) and 13 (bottom) of September 2013. The water vapor is in the mid to upper troposphere and the brighter the imagery, the more saturated the air. Courtesy Axel Graumann, NOAA/NESDIS/NCDC.

Fig. 5. Imagery on 15 September 2013 showing tropical storms Manuel and Ingrid from Moderate Resolution Imaging Spectroradiometer (MODIS) on NASA's Terra satellite. Courtesy NASA. 


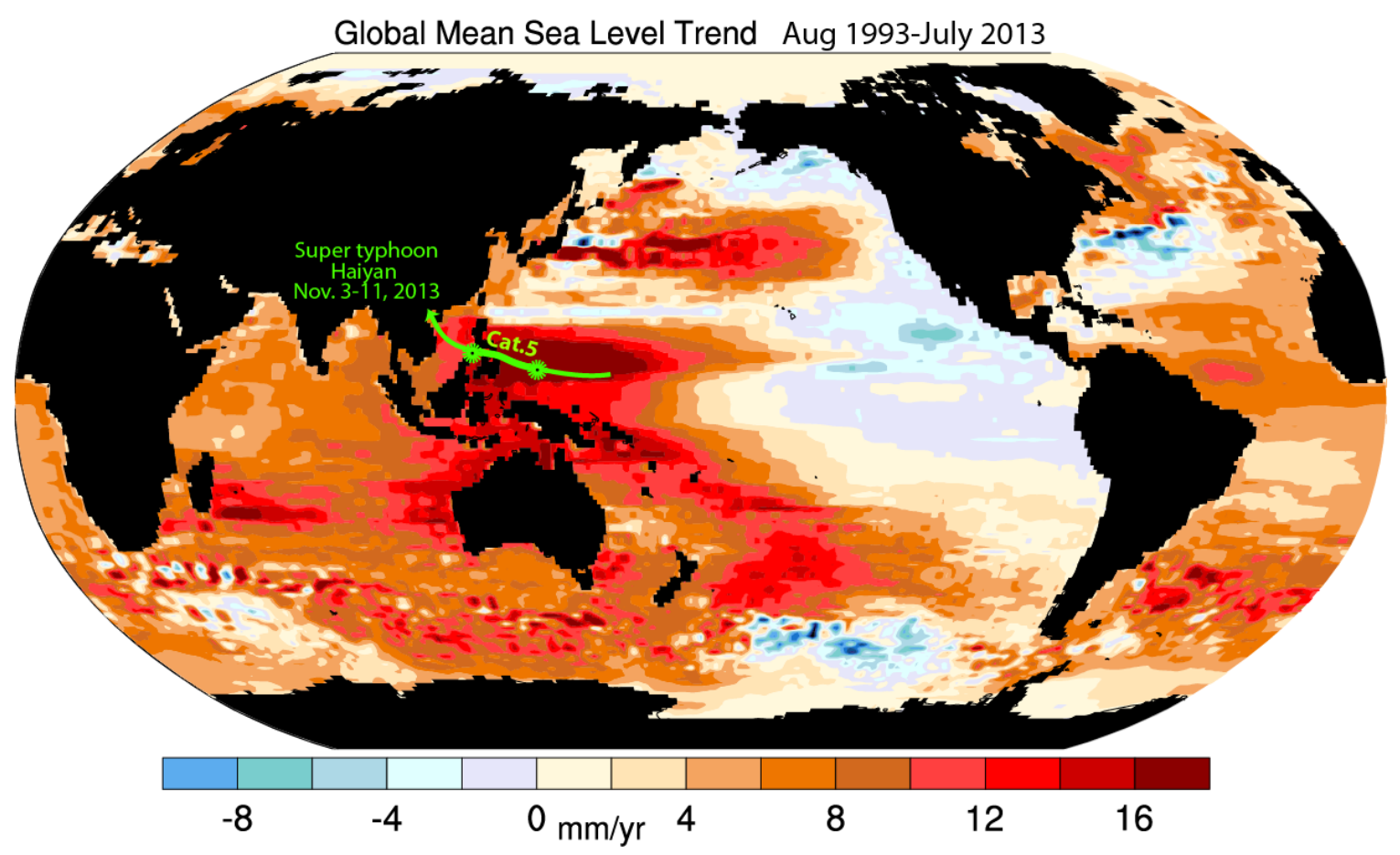

522

523 Fig. 1. Haiyan and sea level: Linear sea level trends from August 1993 to July 2013 in mm/y, 524 from AVISO. The global mean is $3.3 \mathrm{~mm} / \mathrm{y}$ and the track of super Typhoon Haiyan from 3-

52511 November 2013 is shown, with the most intense phase when it was a category 5 storm 526 highlighted.

527

528

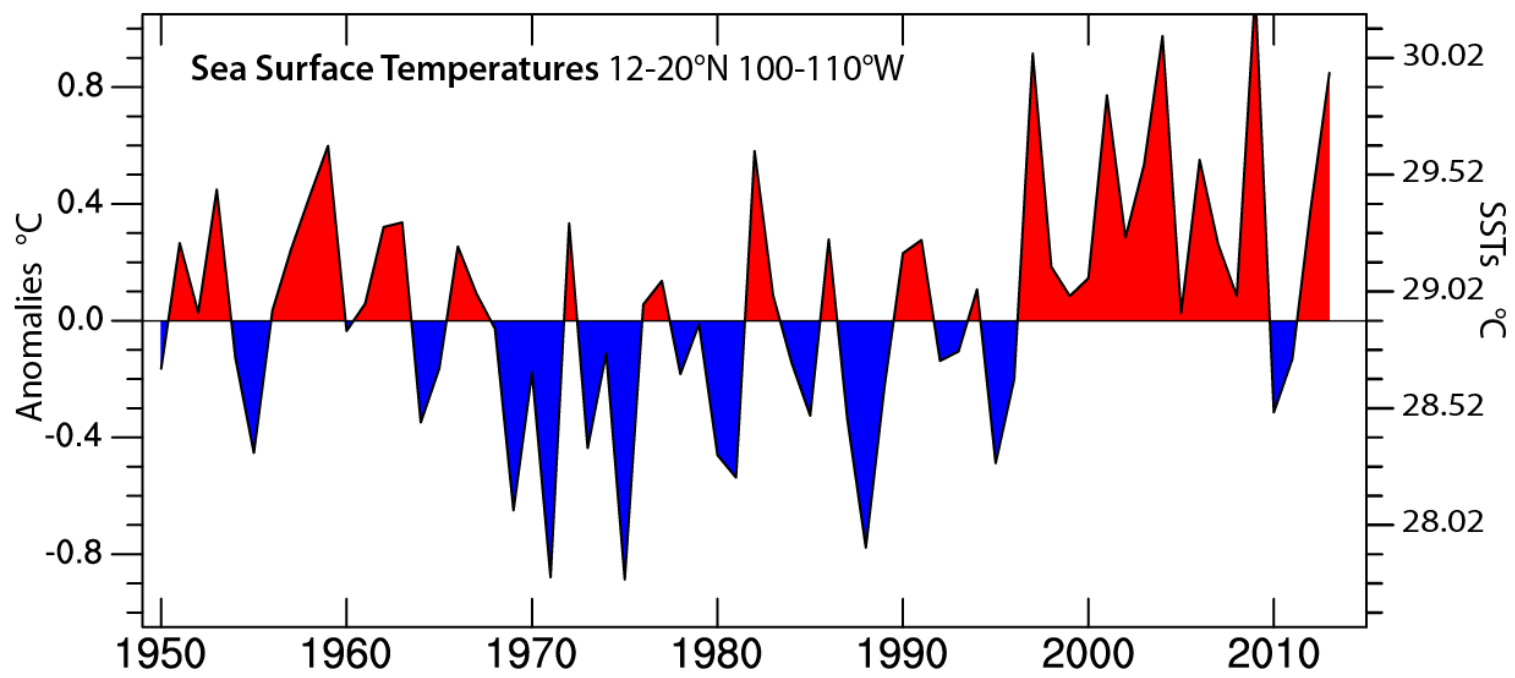

530 Fig. 2. August SSTs for $12-20^{\circ} \mathrm{N} 110-100^{\circ} \mathrm{W}$, just west of Mexico. The mean value is $53128.92^{\circ} \mathrm{C}$ for $1982-1999$. The last value is for 2013. 


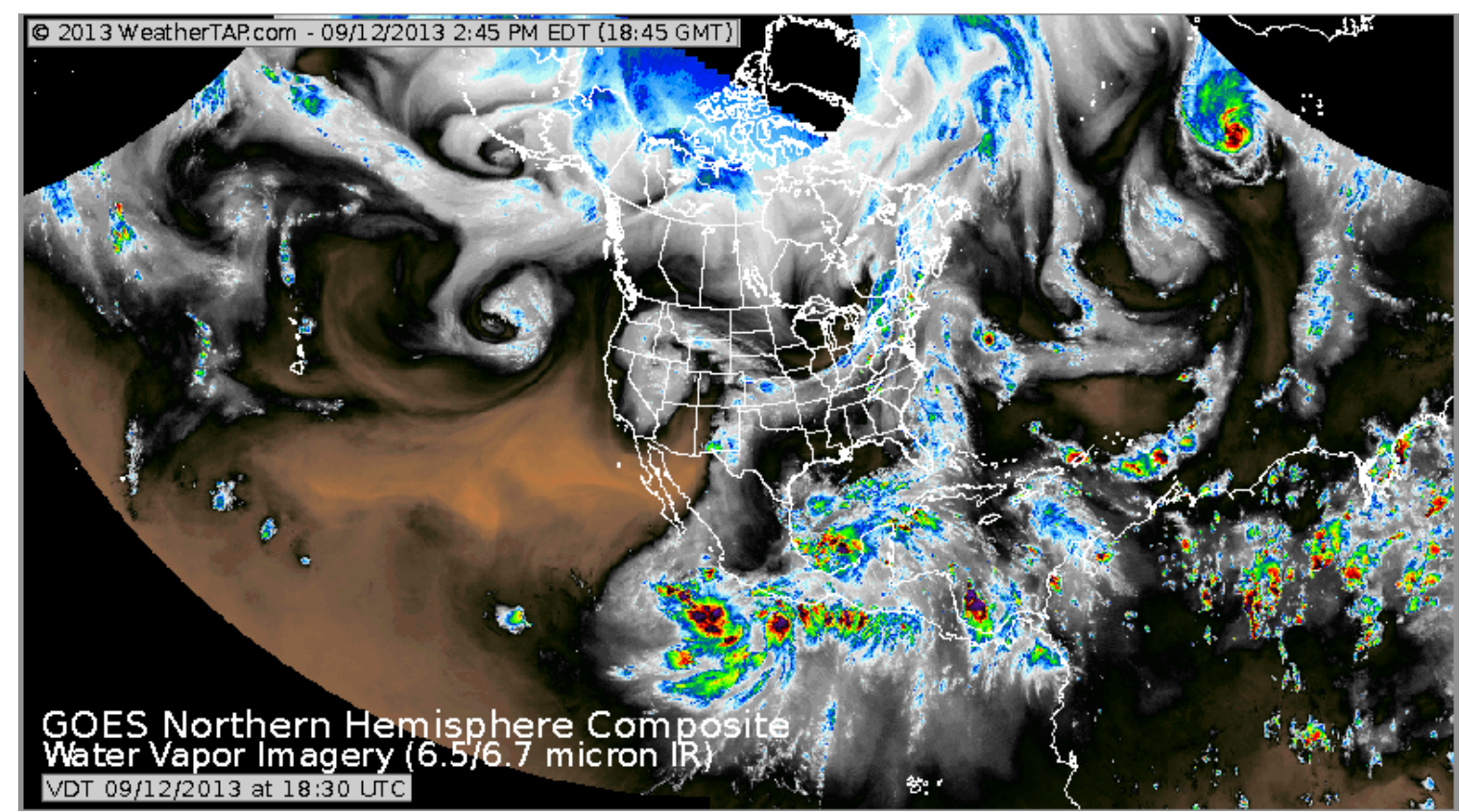

534 Fig. 3. Water vapor channel imagery for 18:45 GMT on 12 September 2013 showing the 535 extensive water vapor and associated activity both west of Mexico and in the Caribbean Sea 536 and the river of moisture from south of Baja, Mexico to eastern Colorado. Courtesy 537 weathertap.com, published with permission. 


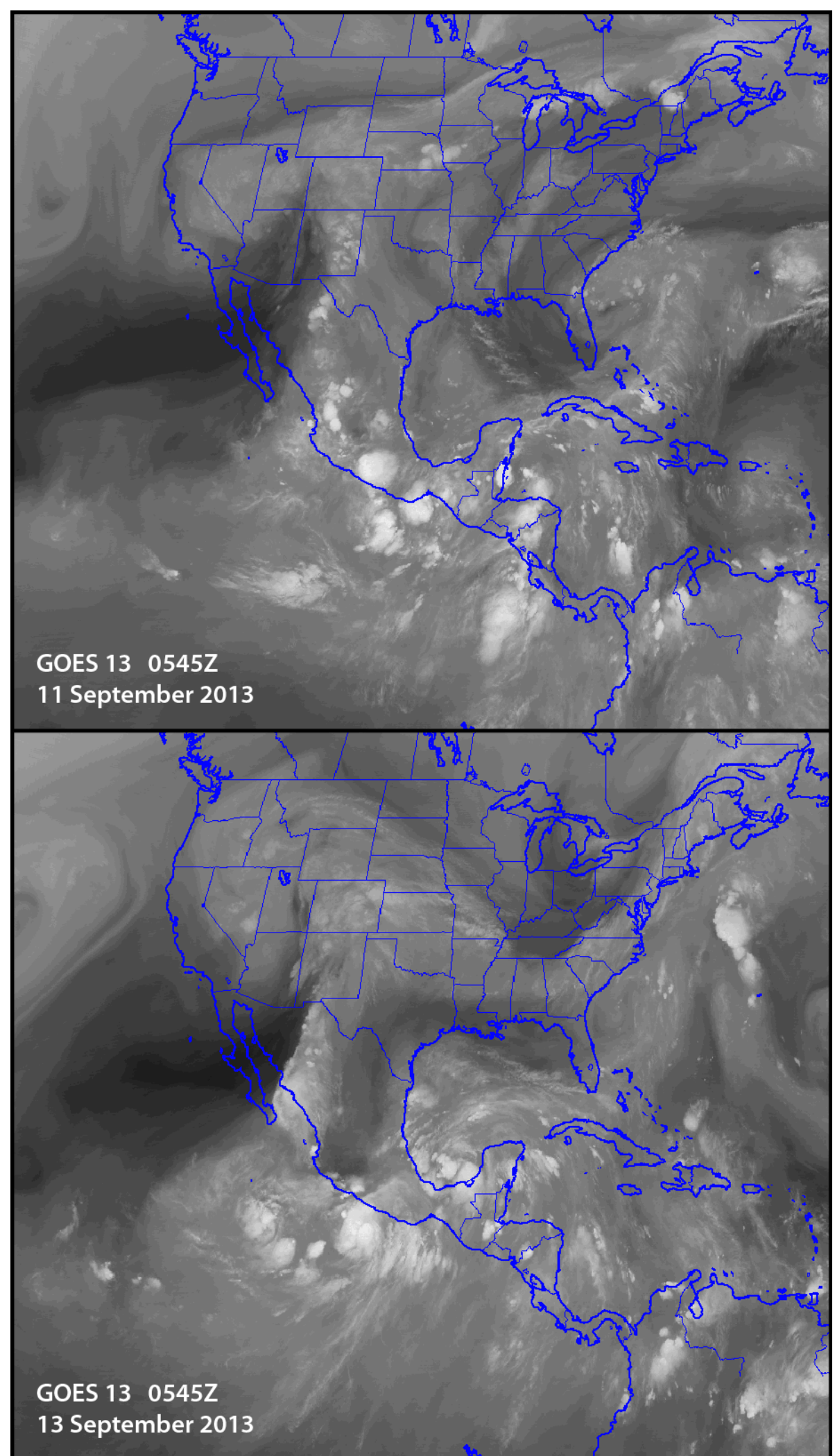

538 Fig. 4. GOES 13 imagery from the 6.5 micron water vapor channel at 0545 GMT on 11 (top)

539 and 13 (bottom) of September 2013. The water vapor is in the mid to upper troposphere 540 and the brighter the imagery, the more saturated the air. Courtesy Axel Graumann, 541 NOAA/NESDIS/NCDC. 


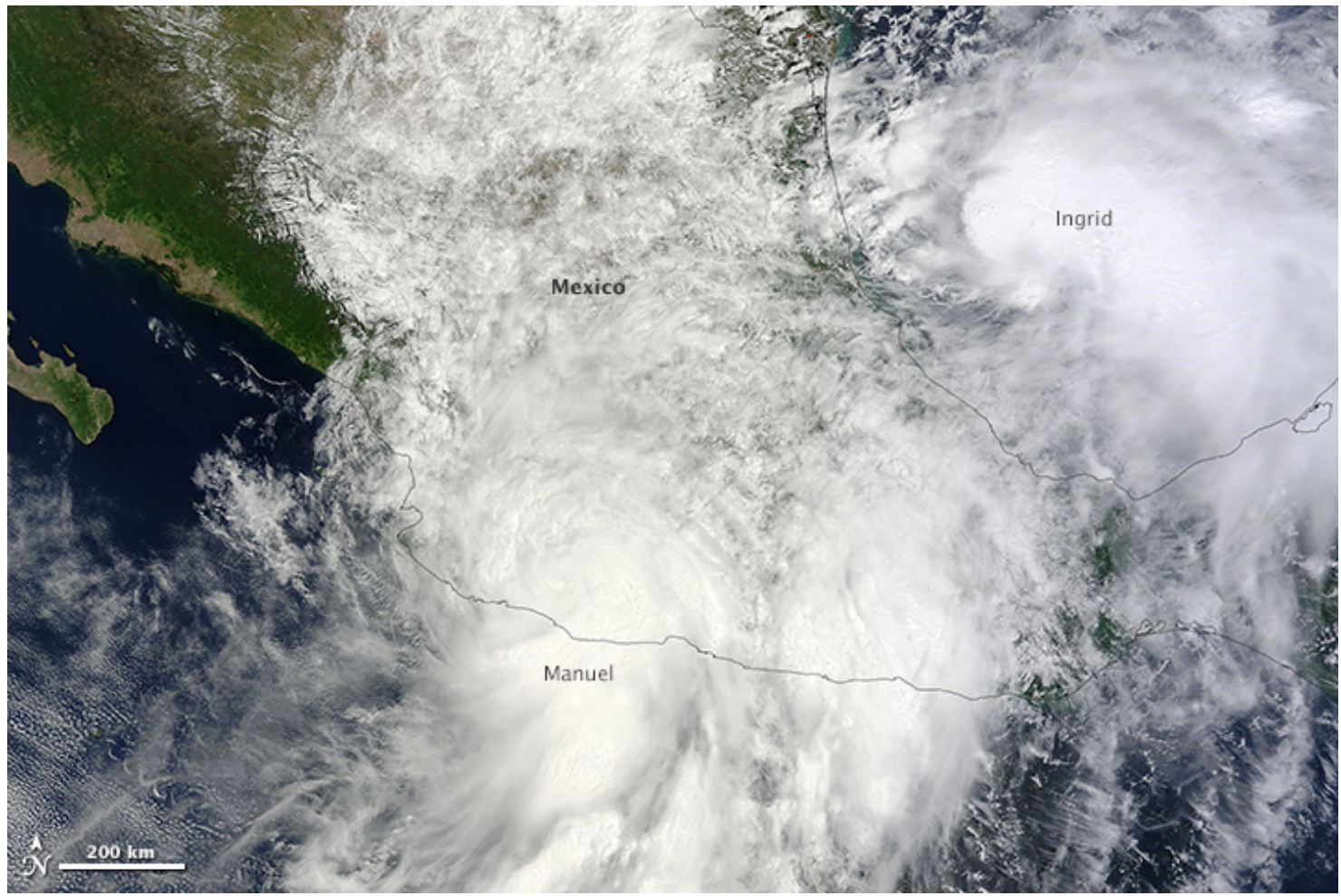

543 Fig. 5. Imagery on 15 September 2013 showing tropical storms Manuel and Ingrid from 544 Moderate Resolution Imaging Spectroradiometer (MODIS) on NASA's Terra satellite. 545 Courtesy NASA. 